\title{
Research Studies in Second Language Writing and in Contrastive Rhetoric
}

\author{
Bambang Yudi Cahyono
}

\begin{abstract}
The major aim of this article is to review studies of second language writing. The first part deals mainly with the process of writing in the second and first languages. The second part concerns contrastive rhetoric. In this second part, the findings of research studies on the relationship of first and second language rhetoric will be presented. Included in the discussion are research studies on contrastive rhetoric in the Indonesian context. The last section of this article concludes the discussion and proposes the implementation of more research on the relationship between Indonesian rhetoric and English rhetoric in essays written by Indonesian learners of English.
\end{abstract}

Keywords: second language writing, contrastive rhetoric, process of writing, Indonesian rhetoric, English rhetoric, process oriented instruction

In its early development, research in the teaching of second language writing was focused on the comparison of different methods of writing instruction in order to find the most effective one (Zamel, 1976). This kind of research was based on the assumption that writing skill can be taught by following a prescribed order of tasks. A typical procedure was to give students an ideal model of written work and to have them write a text conforming to the model. Such an approach was criticized as not revealing the nature of writing as a complex task (Zamel, 1987).

The goal of understanding the nature of writing has led to the emergence of a great number of studies that focus on the examination of what writers do when they write. Two strands of research explore the relationship between the process of writing in the first language (L1) and that in the second language (L2).

\section{Comparison of L2 and L1 Writers}

The purpose of this type of research is to understand whether writers in a second language go through the same process as writers in a first language. Some studies indicate that the composing process of advanced ESL students is similar to that of skilled L1 writers.

Zamel (1983) examined the extent to which advanced ESL students experience writing as a process of discovering and creating meaning, and the extent to which second language factors affect this process. The findings indicated that advanced students understand what writing entails. The strategies that they applied in writing were found to reflect a shared understanding about the process of writing. The students tried to establish meaning first, then to order it, and finally to express it. This process was similar to the writing process of skilled L1 students. 
Raimes (1985) examined how unskilled L2 writers' composing processes differ from those of unskilled L1 writers. Narrative essays of unskilled L2 writers in a college writing course and their think-aloud protocols were analyzed. The results were compared with the work of Perl (1979) who analyzed the writing processes of unskilled L1 writers. Raimes found some similarities among the behaviors of unskilled L2 writers and the behaviors of unskilled L1 writers. The difference was that the unskilled ESL writers did not edit their work as often as the unskilled native speakers. Chenoweth (1987) showed that unskilled ESL writers tend to correct only surface errors of grammar and punctuation, or to change their choice of words. Chenoweth stated that skilled writers edit their papers and work on the overall content to see whether what they want to say is said in a way the reader can understand.

The results of research examining the composing process of L1 and L2 writers reveal that skilled writers in both languages understand that writing is a process of conveying meaning. Skilled writers also realize that writing consists of a series of stages which include planning, draft making, and revising. Zamel (1985) suggests that the way ESL teachers responded to students' writing in the early 1980 s did not reflect an understanding of the nature of this composing process. In the next decade, an examination of the teaching of L2 writing indicates that more ESL teachers reflect their understanding of the writing process in their teaching (Pennington, et al., 1997).

\section{Comparison of Writing in L2 and in L1}

Some researchers have investigated the question of whether the same writers follow a similar process of writing in their second and in their first languages. Studies investigating the relationship between writing in L1 and L2 include Kamimura (1996) and Edelsky (1982).

Kamimura (1996) investigated the composing process of Japanese writers' narrative writing in Japanese and in English. The study questioned whether good writers in Japanese were also good writers in English and the role that learners' proficiency in English played in their composing in English. The subjects were given a series of pictures as a writing prompt and told to write a narrative based on the pictures. It was found that the subjects' Japanese and English writing behaviors were positively correlated. Students who tended to write a large number of words, include more idea units, and produce higher-rated writing in composing in Japanese tended to do so in English as well. Similarly, students who tended to write fewer words, incorporate fewer idea units, and produce lower-rated writing in Japanese tended to do so in English, too. It was also found that the correlation between Japanese and English composing was influenced by the students' English proficiency. The students above a certain threshold composed similarly in Japanese and English, whereas students below the level had considerably more problems in composing in English than in Japanese.

Arndt (1987) examined six Chinese students composing academic written texts in both their L1 and L2 (English). Arndt found that the composing activities of each individual writer remained consistent across languages. Edelsky (1982) analyzed the relationship between first language and second language writing of young writers in a bilingual program. The texts written by the same children in Spanish and in English were analyzed. Edelsky found that what a young writer knows about writing in the first language forms the basis of new hypotheses for writing in another language. Furthermore, Edelsky argued that certain L1 writing processes are used in L2 writing. 
The studies reviewed lead to two major conclusions. Skilled second language and first language writers tend to undergo the same process of writing, and second language writers are likely to follow a process of composing which is similar to that in their first language.

As a result of the development of research in the process of writing, process-oriented instruction has been increasingly advocated in classrooms of second language writing. Advocates of the process-oriented approach view writing as a creative process consisting of a series of stages occurring recursively throughout the process and feeding on one another (Raimes, 1987). This approach focuses on what goes on when learners write and what the teacher can do to help the learners get into the natural writing process.

\section{Pedagogical Concerns of Process Orientation}

As the name suggests, according to Hairston (1982), process-centered instruction focuses on writing processes. This approach teaches strategies of invention and discovery. It views writing as recursive processes in which prewriting, writing, and revision are activities that overlap and intertwine. Furthermore, this approach gives prominence to audience, purpose, and context of writing in the assignment of writing tasks.

In the perspective of the process-oriented approach, instructors are encouraged to intervene in students' writing during the processes of generating ideas, discovering purpose, and integrating ideas into the final product of writing. As a consequence of the emphasis on audience and purpose, teachers evaluate the written product by how well it fulfills the writer's intention and meets the audience's needs. Teachers provide positive intervention for the students' writing by providing feedback which, according to research studies, turns out to be effective (Dheram, 1995; Boughey, 1997).

Sharing her classroom experience in dynamic writing, Wijaya (2000) argues that that collaborative activities are useful to help learners generate ideas in prewriting process. Dheram (1995) found that learners made revisions following feedback both in form and in content. Form revisions are mostly sentence-level and do not affect meaning, while content revisions are meant to make meaning clearer, to emphasize tone and style, and to add arguments with new supporting details. It was evident from the revised versions that learners used feedback as a reference for adding, deleting, and rearranging their ideas. Boughey (1997) found that feedback was crucial in getting students to be more explicit and in making learners express propositions in their writing more rigorously. Villamil and Guerrero (1998) investigated the impact of peer revision on writers' final drafts. The results showed that points of revision during the peer interaction were selected and incorporated into final versions.

The process-oriented approach has several advantages to be considered in the teaching of second language writing. The process-oriented approach motivates students to write even in cases where they may initially experience fear of doing so, such as fear of making errors; encourages learners to take pride in their writing, so they can work at developing a piece of writing which is as good as they can make it; provides students with techniques to generate ideas and organize their thoughts; and promotes positive, productive teacher feedback rather than judgmental comments (Caudery, 1995).

\section{Criticism of Process-Oriented Instruction}


In spite of the popularity of process-oriented instruction, it should be noted that this approach has limitations. As a result of giving prominence to the process, writing can become cumbersome and over-lengthy in class. Furthermore, the emphasis on multiple drafts can make the work on a particular text boring to students, especially when they know that the audience is still the teacher. Moreover, the need to provide constructive individual feedback during the writing process places an additional burden on the teacher. In addition, the approach can suggest that writing is inevitably a long process, in which a text is gradually refined. Finally, the process approach is not suitable for writing examination essays and is not applicable to all types of writers and tasks (Caudery, 1995; Horowitz, 1986).

Realizing that the process-oriented approach only partially helps solve problems in writing in a second or foreign language, researchers take into account the importance of target language rhetorical structures. Chaudron (1987) suggests that in the application of writing processes learners should also be helped by being provided with a certain amount of target language rhetorical structure based on the learners' current state of knowledge. In the same vein, Connor (1987) concludes that text analysis of written products and process-centered research are complementary and are both needed for an integrated theory of writing. Leki (1991) emphasizes the need for adopting both processoriented and product-oriented instruction in order not to exclude either approach.

To consider products in the teaching of writing will provide other advantages as well. According to Chaudron (1987), knowledge about target language discourse forms will help learners cope with unexpected limits on their ability to express their thoughts. Raimes (1985) recommends that the students be taught not only how to explore ideas in writing, but also how to include rhetorical and linguistic features after the ideas have found some form. According to Leki (1991), due to the possibility of transfer of L1 writing strategies to the L2 context, attention to target language forms would make ESL learners' writing more effective in the new context.

Studies of the rhetorical patterns of ESL learners' writing indicate that second language learners are likely to produce modes of discourse preferred in their own culture (Kaplan, 1966; Ostler, 1987). The study of the influence of first language rhetorical strategies on second language learners' writing patterns is the area of contrastive rhetoric.

Contrastive rhetoric makes it possible to develop a writing pedagogy fostering the construction of rhetorical schemata that correspond to those of English-speaking readers. Unlike the process-oriented approach that induces the construction of schemata indirectly, text analysis suggests that schemata can be directly taught. It does not mean that textual orientation gears the students to ignore the content. Rather, rhetorical patterns help learners shape their ideas and provide them ways to compare and analyze patterns and variations on patterns which advance meaning. As the students are directed to write according to patterns accepted in the target community, the audience also becomes another important concern of contrastive rhetoric.

\section{Contrastive Rhetoric}

Contrastive rhetoric examines problems in composition encountered by second language writers and attempts to explain them by referring to the rhetorical strategies of the first language (Connor, 1996: 5). The emergence of contrastive rhetoric can be traced to Kaplan (1966). Kaplan stated that English paragraph development is different from paragraph development in other linguistic systems. To support his statement, Kaplan analyzed compositions written in English by international students. Kaplan 
tentatively identified five types of paragraph development for five language groups. Kaplan suggested that the different thought development that emerged in the students' writing could be represented by the graphic form shown in Figure 1.

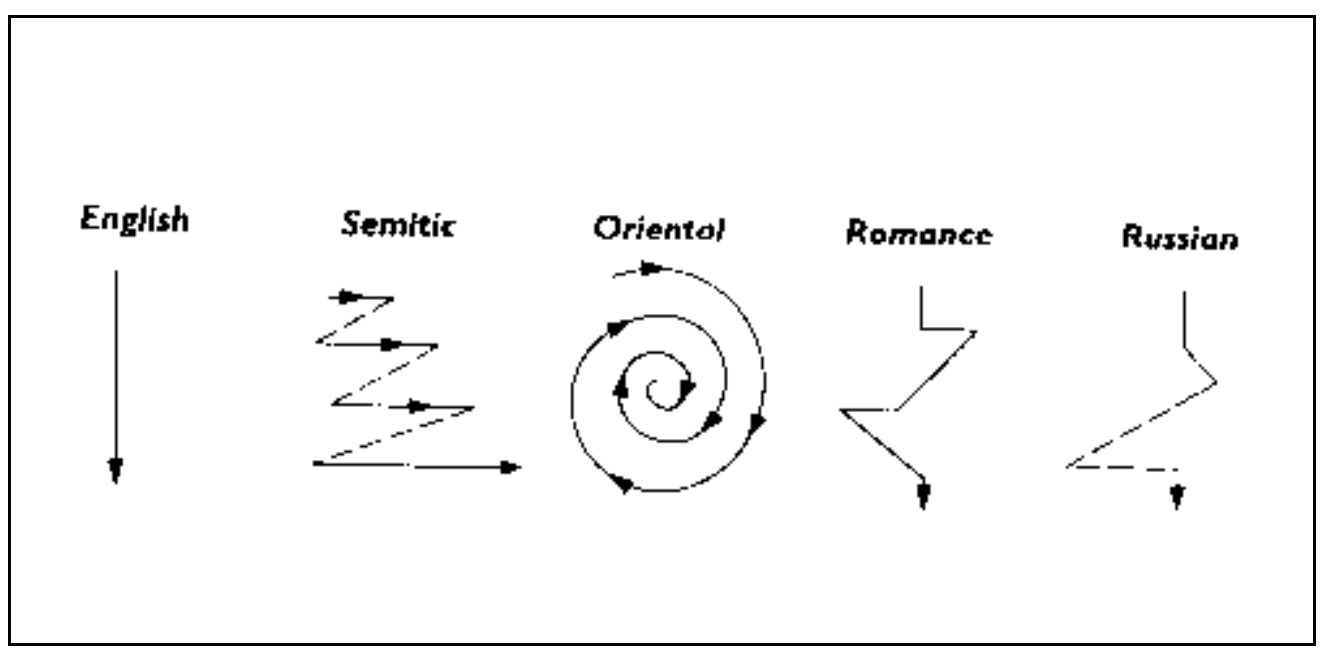

Figure 1. Rhetorical patterns of different languages (Kaplan, 1966)

Kaplan (1966) hypothesized that in expository writing "each language and each culture has a paragraph order unique to itself, and that part of the learning of the particular language is the mastering of its logical system" (p. 14). According to Kaplan, in English compositions the flow of ideas occurs in a straight line from the opening sentence to the last sentence. The graph also suggests that in compositions written in other linguistic systems the flow of ideas happens in various modes. In the compositions written in Semitic languages, the ideas were conveyed in a zigzag line, indicating frequent uses of parallelism. In the Oriental pattern, the ideas were presented circularly - reflecting an indirect approach - in order to get to the main points. The Romance and Russian patterns also showed different modes of idea presentation. In these two linguistic systems, there is freedom to digress and to introduce extra materials. The point that Kaplan (1966) tried to make is that "paragraph developments other than those normally regarded as desirable in English do exist" (p. 14). Although English has a different pattern, as far as Kaplan was concerned, "It is not a better nor a worse system than any other, but it is different" (p. 3).

Kaplan's (1966) article has come to be known popularly as the "doodles article". It has come under much criticism. According to Connor (1997), Kaplan was criticized because he used overgeneralizing terms such as Oriental. He was also considered to have erred in inferring native language organization on the basis of ESL students' essays. Furthermore, Kaplan was faulted for overemphasizing cognitive factors "at the expense of sociocultural factors (e.g., schooling) to explain preferences in rhetorical conventions" (p. 201).

However, Kaplan's (1966) article did not lose its significance as the first article that attempted to analyze how native thinking and discourse structures manifest themselves in the writing of ESL learners (Söter, 1988). In 1987, Kaplan stated that he had become even more convinced that there was validity to his original idea. In his more recent opinion, Kaplan $(1997 ; 1988)$ argues that all of the various rhetorical modes are possible 
in any language. However, the forms do not occur with equal frequency; the "preferred cultural patterns" (Ostler, 1990; Connor \& McCagg, 1987) are the modes which are most likely to be used. Both Kaplan's "doodles article" and his more recent arguments have in fact motivated a great number of research studies. Eventually, such research studies have shaped contrastive rhetoric into a specific field of study in second language acquisition.

Research studies of the relationship between first and second language rhetoric are of distinct types. The first type involves writers from two different cultures writing in the same language. In most of these studies, researchers analyze texts of English as a second language and those of English as a first language. The other type of study involves writers from the same culture writing in two different languages. ESL texts and texts written in the same writers' L1 are compared. The two types of study are important as they permit us to explore such issues as the extent to which differences in rhetorical strategies are due to differences in cultural patterns of thought and expression, differences in the languages themselves, or differences in the proficiency levels of writers.

\section{Comparative Studies of ESL and L1 English Texts}

In line with Kaplan (1966), various studies have compared L1 English texts and ESL texts written by a group of students from different L1 backgrounds. The purpose of such studies is to discover cross-cultural differences in the rhetorical patterns. As reported by Silva (1997), Norment's (1984) study supported Kaplan's claims about the thought patterns of ESL and L1 English writers. Norment found distinct linear organizational patterns in the texts of L1 English writers, centrifugal patterns in those of L1 Chinese writers, and linear patterns with tangential breaks in those of L1 Spanish writers. Silva (1997) also reported a study by Burtoff (1983) who found patterns similar to those posited by Kaplan in the texts written in English by native speakers of English, Arabic, and Japanese.

Ostler (1987) compared the structure of 22 expository essays written in English by Saudi Arabian students with those written by native English speakers. The T-unit - the shortest possible sentential unit which is still grammatical - and the discourse unit - a unit containing several ideas related to each other at both syntactic and semantic levels - were used to analyze the texts. The analysis showed that the mean length of T-units for Arabic speakers was $70 \%$ higher than that for English speakers. In addition, no English essay contained more than two discourse units, while $77 \%$ of the Arabic essays had three, almost half had four, and some had five discourse units. Three years later, Ostler (1990), reported by Kubota (1998), compared ESL essays written by four language groups. Ostler found rhetorical differences in the essays written by English, Arabic, Spanish and Japanese speakers. From the two research studies, Ostler concluded that ESL students wrote according to the styles preferred in their own cultures.

Söter (1988) examined simple narrative stories written by students in grades 6 and 11 in Sydney, Australia. The students were Vietnamese, Arabic-speaking Lebanese, and native English-speaking students. Forty-five compositions were analyzed for rhetorical patterns in the "storygraph". The storygraph analysis was designed to determine the general structures of plot and story development and the inclusion of information that is not typical of English narratives. Söter found that the stylistic and rhetorical patterns of narration of the Vietnamese and the Arabic students were different in various respects 
from those of native English writers. Söter demonstrated that the students' prior knowledge of literacy and literary experiences in their first language had an impact on their current experiences and on their writing performance.

The assumption behind the comparative studies of ESL and L1 English texts is that if distinct patterns emerged from the English texts written by different L1 groups, they would provide evidence that such rhetorical patterns exist in their L1. These patterns are then carried into L2 writing. The findings of such studies are hypothesized to be useful in determining the implications of any differences for the pedagogy of second language writing. However, it is essential to confirm that the differences in ESL and L1 writing, in fact, come from the transfer of L1 writing patterns. Studies addressing this question are presented in the next section.

\section{Investigation of ESL Texts and L1 Texts}

The second type of research study deals with the comparison of ESL texts and texts written by the same writers in the first language. The central question is whether rhetorical patterns similar to those in $\mathrm{L} 1$ texts are produced when the second language learners write ESL essays. Support for the notion of an L1 influence was found by Indrasuta (1988) who examined narrative writing by Thai advanced secondary school students in Thai and in English. Linguistic, stylistic, and discourse components were considered as factors that function together to form a narrative text. Indrasuta concluded that ESL essays and L1 Thai essays were similar with regard to narrative style and function and were different in terms of linguistic components.

Indrasuta's findings were confirmed by Mohan and Lo (1985) who analyzed the academic writing of Chinese students. They found that the lack of English writing skills of these students was not because of their cultural thought patterns, but due to factors of language development. The authors' investigation of composition practices in Hong Kong and British Columbia demonstrated that the emphasis of writing instruction was more on sentence-level accuracy than on discourse organization. Mohan and Lo concluded that "transfer of rhetorical organization is more likely to help than to interfere," (p. 259). They also suggested further research to examine whether students who are skillful writers in their L1 have an advantage in L2 composition.

Bickner and Peyasantiwong (1988) investigated reflective writing in English and Thai. Their examination of the structure of the writing samples revealed that, although the English and the Thai essays began with a topic sentence followed by supporting ideas, the nature of supporting ideas was different. The Thai writers defined terms and listed various attributes of the topic under discussion without providing evidence for their argument. Their conclusions were frequently offered as suggestions for changes in behavior, along with the benefits of the change. In contrast, the writers of English essays did not offer definitions for the terms used as they all accepted them as given. Most of the English essays began with a topic sentence and followed that sentence with others giving examples illustrating the point. In addition, the conclusions offered were mostly speculative, a type of reasoning that was not found in the Thai essays.

Kachru (1988) examined written expository texts in Hindi to illustrate the differences between the conventions of writing in English and in Hindi. Two genres of expository writing were analyzed, i.e. scientific text and literary criticism. Kachru found that the conventions of writing in Hindi appeared to be different from those of English in the two genres examined. Kachru argued the difference is not always categorical in that the 
structure of a paragraph in Hindi is not always circular. In the Hindi texts, there are paragraphs exhibiting the straight linear structure of English paragraphs and there are paragraphs reflecting the circular structure.

Other studies of contrastive rhetoric in this stream include, among others, Clyne (1983), Leap (1983), and Hinds (1983). Clyne (1983) reported his comparison of upper secondary school essays and textbooks in English and in German. Clyne found that form is of greater importance in educational discourse in English-speaking countries than in German-speaking countries. As Clyne stated, linearity and lack of redundancy play a more significant role in English. Clyne also argued that issues relating to linearity cannot be divorced from the grammatical structures of the languages. Leap (1983) reported that the written English of American Indian students contained a set of phonological and grammatical features related to their first language. Hinds (1983) found that Japanese expository prose contained details in the initial parts, burying the thesis in the prose. It also contained digressions and unrelated information which were not expected by English readers.

\section{Studies on EFL Rhetoric in the Indonesian Context}

It is difficult to find studies analyzing Indonesian texts and EFL texts. However, a few studies reported on aspects of rhetoric in EFL essays written by Indonesian university students learning English (Sulistyaningsih, 1997; Latief, 1990; and Ignatius, 1999). One study compared English newspaper articles written by Indonesian- and English-speaking writers (Kartika, 1997).

Sulistyaningsih (1997) examined rhetoric in expository essays of fourth-year university students majoring in English. The results showed that among 11 introductory paragraphs analyzed, 64 percent had good thesis statements. The other 36 percent contained partial thesis statements. Among 32 developmental paragraphs analyzed, 88 percent had good topic sentences. However, among all of the developmental paragraphs, only 78 percent of them reflected the idea in the thesis statement. Finally, among the 11 concluding paragraphs studied, 82 percent were good concluding paragraphs in the sense that they consisted of the main points or restatement of the thesis and additional comments about the topic.

Latief (1990) examined the rhetorical quality of argumentative essays written by Indonesian university students. The participants were second-, third-, and fourth-year students majoring in English. A minimum acceptable quality was determined for this discourse mode. It was expected that each of the argumentative essays would show the position the writer was taking, provide at least one piece of relevant evidence, and show the relationship between the position taken and the evidence. Latief found that the majority of the argumentative essays met this minimum acceptable quality. Latief also found that the argumentative essays written by the fourth-year students were the best.

Ignatius (1999) investigated the features of English academic writing by Indonesian students of the English department of the Graduate School of the State University of Malang enrolled in the 1995-1996 and 1996-1997 academic years. The study revealed that in general the rhetorical structures of the essays reflected the overall feature of the English academic-writing essay, although they did not always contain important elements. The rhetorical development of ideas in the essays did not entirely follow the linear staging of the information as expected by English-speaking readers. Many essays were marked by indirect approaches such as circular and digressive developments. 
The various analyses of ESL and L1 texts indicate that some aspects of writing in L1 texts are similar to those in ESL texts. Thus, there is some support for the hypothesis that characteristics of ESL texts may be traced to their L1 writing pattern. In addition, the difference in ESL texts and L1 texts might also be attributable to factors of language development.

Concerning Indonesian rhetoric, Indonesian learners tend to know the rhetorical components that essays should contain, such as a thesis statement, developmental paragraphs, and topic sentences. However, the rhetorical development of ideas in the essays does not entirely conform to the expectations of English-speaking readers. From the conclusions, it is necessary that more studies be conducted to investigate the relationship between Indonesian rhetoric and English rhetoric in essays written by Indonesian learners of English.

\section{References}

Arndt, V. (1987). Six writers in search of text: A protocol-based study in L1 and L2 writing. ELT Journal, 41, 257-267.

Bickner, R., \& Peyasantiwong, P. (1988). Cultural variation in reflective writing. In A.C. Purves (Ed.), Writing across languages and cultures: Issues in contrastive rhetoric. Newbury Park, CA: Sage. 160-174. 
Boughey, C. (1997). Learning to write by writing to learn: A group-work approach. ELT Journal, 51, 126-134.

Burtoff, M. (1983). The logical organization of written expository discourse in English: A comparative study of Japanese, Arabic, and Native-Speaker Strategies. Dissertation. Ann Arbor: Georgetown University.

Caudery, T. (1995). The process approach. Paper presented in the summer school on writing in the classroom, July 1995. Guildford: University of Surrey.

Chaudron, C. (1987). Analysis of product and instructional approaches in writing: Two articles on the state of the art. TESOL Quarterly, 21, 673-675.

Chenoweth, N. A. (1987). The need to teach rewriting. ELT Journal, 41, 25-29.

Clyne, M.G. (1983). Contrastive studies: English and German. In R.B. Kaplan (Ed.), Annual review of applied linguistics. Rowley, MA: Newbury House. 38-49.

Connor, U. (1987). Research frontiers in writing analysis. TESOL Quarterly, 21, 677696.

Connor, U. (1996). Contrastive rhetoric: Cross-cultural aspects of second-language writing. Cambridge: Cambridge University Press.

Connor, U., \& McCagg, P. (1987). A contrastive study of English expository prose paraphrases. In U. Connor \& R. B. Kaplan (Eds.), Writing across languages: Analysis of L2 text. Reading, MA: Addison-Wesley. 73-86.

Dheram, P. K. (1995). Feedback as a two-bullock cart: A case study of teaching writing. ELT Journal, 49, 160-168.

Edelsky, C. (1982). Writing in a bilingual program: The relation of L1 and L2 texts. TESOL Quarterly, 16, 211-228.

Hairston, M. (1982). The winds of change: Thomas Kuhn and the revolution in the teaching of writing. College Composition and Composing, 33, 76-88.

Hinds, J. (1983). Linguistics and written discourse in English and Japanese: A contrastive study (1978-1982). In R.B. Kaplan (Ed.), Annual review of applied linguistics. Rowley, MA: Newbury House. 78-84.

Horowitz, D. (1986). Process, not product: Less than meets the eye. TESOL Quarterly, $20,141-144$.

Ignatius, H. (1999). English academic writing features by Indonesian learners of English. Dissertation. Malang: Graduate Program of State University of Malang, Indonesia. 
Indrasuta, C. (1988). Narrative styles in the writing of Thai and American students. In A.C. Purves (Ed.), Writing across languages and cultures: Issues in contrastive rhetoric. Newbury Park: Sage.

Kachru, Y. (1988). Writers in Hindi and English. In A.C. Purves (Ed.), Writing across languages and cultures: Issues in contrastive rhetoric. Newbury Park, CA: Sage. 109-135.

Kamimura, T. (1996). Composing in Japanese as a first language and English as a foreign language: A study of narrative writing. RELC Journal, 27, 47-69.

Kaplan, R.B. (1966). Cultural thought patterns in intercultural education. Language Learning, 16, 1-20.

Kaplan, R.B. (1987). Cultural thought pattern revisited. In U. Connor \& R. B. Kaplan (Eds.), Writing across languages: Analysis of L2 text. Reading, MA: AddisonWesley. 9-21.

Kartika, O. R. (1997). A study on rhetoric by Indonesian and English native writers in the Jakarta Post. Thesis. Malang: English Department of State University of Malang, Indonesia.

Kubota, R. (1998). An investigation of L1-L2 transfer in writing among Japanese university students: Implications for contrastive rhetoric. Journal of Second Language Writing, 7, 69-100.

Latief, M.A. (1990). Assessment of English writing skills for students of English as a foreign language at the Institute of Teacher Training and Education IKIP MALANG Indonesia. Dissertation. Iowa: The University of Iowa.

Leap, W. L. (1983). Contrastive studies: English and American Indian languages. In R.B. Kaplan (Ed.), Annual review of applied linguistics. Rowley, MA: Newbury House. 24-37.

Leki, I. (1991). Twenty-five years of contrastive rhetoric and writing pedagogies. TESOL Quarterly, 25, 123-143.

Mohan, B. A., \& Lo, W.A. (1985). Academic writing and Chinese students: transfer and developmental factors. TESOL Quarterly, 19, 515-534.

Norment, N. (1984). Contrastive analysis of organizational structures and cohesive elements of in native and ESL Chinese, English, and Spanish writing. Dissertation. Ann Arbor: Fordham University.

Ostler, S.E. (1987). English in parallels: A comparison of English and Arabic prose. In U. Connor \& R. B. Kaplan (Eds.), Writing across languages: Analysis of L2 text. Reading, MA: Addison-Wesley. 169-185. 
Ostler, S.E. (1990). The contrastive rhetoric of Arabic, English, Japanese and Spanish. Paper presented at the 24th Annual TESOL Convention, San Francisco.

Pennington, M.C., Costa, V., So, S., Shing, J.L.W., Hirose, K., \& Niedzielski, K. (1997). The teaching of English-as-a-second-language writing in the Asia-Pacific region: A cross-country comparison. RELC Journal, 28, 120-143.

Perl, S. (1979). The composing processes of unskilled college writers. Research in the Teaching of English, 13, 317-336.

Raimes, A. (1985). What unskilled ESL students do as they write: A classroom study of composing. TESOL Quarterly, 19, 229-258.

Raimes, A. (1987). Language proficiency, writing ability, and composing strategies: A study of ESL college student writers. Language Learning, 37, 439-468.

Silva, T. (1997). Differences in ESL and native-English-speaker writing: The research and its implications. In C. Severino, J. C. Guerra, \& J. E. Butler (Eds.), Writing in multicultural settings. New York: The Modern Language Association of America. 209-219.

Söter, A. O. (1988). The second language learner and cultural transfer in narration. In A.C. Purves (Ed.), Writing across languages and cultures: Issues in contrastive rhetoric. Newbury Park, CA: Sage. 177-205.

Sulistyaningsih. (1997). A descriptive study on rhetoric in students' expository essays. Thesis. Malang: English Department of State University of Malang, Indonesia.

Villamil, O.S., \& Guerrero, M.C.M. de. (1998). Assessing the impact of peer revision on L2 writing. Applied Linguistics, 19, 491-514.

Wijaya, J. (2000). Collaborative work in prewriting stage. Kata, 2, 40-43.

Zamel, V. (1976). Teaching composition in the ESL classroom: What we can learn from research in the teaching of English. TESOL Quarterly, 10, 67-76.

Zamel, V. (1985). Responding to student writing. TESOL Quarterly, 19, 79-101.

Zamel, V. (1983). The composing processes of advanced ESL students: Six case studies. TESOL Quarterly, 17, 165-187.

Zamel, V. (1987). Recent research in writing pedagogy. TESOL Quarterly, 21, 697-715. 